\title{
EL SANTO OFICIO DE UNAMUNO EN EL TEATRO DE JOSÉ BERGAMÍN
}

\author{
María Teresa Santa María Fernández \\ Universidad de La Rioja ${ }^{1}$
}

\begin{abstract}
RESUMEN
La admiración de José Bergamín hacia su maestro Unamuno fue constante y manifiesta a lo largo de su vida. Son numerosos los artículos, ensayos y citas en sus poemas donde podemos encontrar la huella de don Miguel. Esa presencia adquiere unas notas particulares en el teatro del escritor madrileño: gusto por las paradojas, juego de palabras pero, sobre todo, un concepto del deber como escritores que no les permite quedarse al margen de la realidad que les tocó a ambos vivir. Desde sus textos de Vanguardia hasta sus piezas dramáticas en el exilio, la huella de Unamuno se hace patente y duradera, tal y como tendremos ocasión de comprobar.

PALABRAS ClAVE: José Bergamín, Unamuno, teatro, influencias, concepción dramática.
\end{abstract}

\section{Abstract}

José Bergamín admired Miguel de Unamuno all his life. He wrote a lot of papers, articles, poems in which Unamuno's inspiration is evident. Bergamín even called Miguel de Unamuno his «maestro». And this presence is very important and peculiar in Bergamín's plays: paradoxes, word games and, above all, the idea of writing like an «oficio», work that implicates writers with his world and time. From his first Vanguardia's plays until his dramatic plays during his exile, Unamuno remains in many characters, plots and images, as we will prove later.

KEY Words: José Bergamín, Unamuno, theater, comparative literature, dramatic ideas.

Resulta por todos sabido la admiración que sentía José Bergamín (1895-1983) por Miguel de Unamuno y su reconocimiento como maestro de expresión, de vida y de pensamiento. En las próximas páginas intentaremos comprender cómo se refleja en el teatro bergaminiano las, para él, grandes enseñanzas del que fue, por encima de todo, maestro y amigo. Empezaremos con el concepto de teatro que ambos defenderán como compromiso y «oficio divino»; después comentaremos el gusto por lo paradójico y por jugar con las palabras encima del escenario; y, por último, terminaremos con la concreción que realiza Bergamín de las enseñanzas sobre teatro del escritor vasco.

Recibido: 10-02-2016 / Aceptado: 16-06-2016

\footnotetext{
${ }^{1}$ Este artículo se inscribe dentro del proyecto «La historia de la literatura española y el exilio republicano de 1939» (FFI2013-42431-P).
} 


\section{El SANTO OFICIO DE ESCRIBIR}

El santo oficio de escribir que es santo oficio de inquirir en las palabras y con ellas el lenguaje que expresa porque exprime las conciencias humanas.

La cita anterior aparece en «Miguel de Unamuno y el santo oficio del escritor» ${ }^{2}$ que Bergamín incluyó en 1943 como prólogo a Cuenca ibérica. Destaca en todo el texto una defensa, común en ambos autores, de apartarse de los lugares comunes y de devolver a las palabras sus múltiples matices y significados, para conseguir, de esta forma, un único objetivo, pensar y alcanzar la verdad: « ¿Santísimo oficio el de escribir que es inquirir verdad!».3

Este ideario de escritor comprometido con el lenguaje y el pensamiento supone un rasgo importante y destacable, en un momento en que ya el autor madrileño se había señalado como contrario a la deshumanización del arte promulgada por Ortega y al encierro del poeta en su torre de marfil como deseaba Juan Ramón Jiménez. De esta forma, Bergamín encuentra en el maestro Unamuno un modelo de quehacer literario afín a su pensamiento, pero también a su personalidad inquisidora y ávida de jugar con las palabras. Su defensa del analfabetismo como forma de volver a la veta pura del lenguaje nos recuerda en seguida no solo al artículo que publicó en 1933 sobre esta cuestión ${ }^{4}$ sino, sobre todo, las dos visiones enfrentadas sobre el arte de entender la lengua y el lenguaje que encontramos en una de sus primera obras teatrales, Los filólogos.

La farsa de los filólogos o Los filólogos está fechada en el 1925. El texto se dio por perdido durante muchos años, pero Nigel Dennis, gracias a la colaboración de la viuda de don Antonio Rodríguez-Moñino, pudo rescatarlo y publicarlo con posterioridad. ${ }^{5}$ $Y$ resulta interesante para el tema que nos ocupa porque en esta farsa, al estilo de Aristófanes, aparecen como personajes de la obra «Don Miguel de Unamuno» y José Bergamín, caracterizado, en su caso, como «El Mirlo».

Esta «comedia», como la define su autor, va dedicada a Pedro Salinas y pone sobre la escena a grandes pensadores y escritores españoles de principios del siglo pasado. Por un lado, aparece el bando de «Los filólogos», caricaturizados por Bergamín, y entre quienes se incluyen «El Maestro Inefable don Ramón Menéndez»,

\footnotetext{
2 Prólogo de Bergamín al libro de Miguel de Unamuno, Cuenca ibérica (lenguaje y paisaje), México, Séneca, 1943. Recogido en Bergamín, J., Prólogos epilogales, N. Dennis (ed.), Valencia, Pre-Textos, 1985, p. 91.

3 Bergamín, J., Prólogos epilogales, ob. cit., p. 95.

4 Bergamín, J., «La decadencia del analfabetismo», en Cruz y Raya, Madrid, 3, junio 1933, pp. 61-94.

5 Madrid, Turner, 1978. Pero citaremos por el texto que se recoge en José Bergamín. Un teatro peregrino, en Cuadernos El Público, 39, Madrid, abril 1989, pp. 43-58. También lo edita Paola Ambrosi en Bergamín, J., Teatro de vanguardia (Una noción impertinente), Valencia, Pre-Textos, 2004, pp. 261-295.
} 
«El Doctor Américus» y «El Profesor Tomás Doble». ${ }^{6}$ Por el otro, nos encontramos con «El Espíritu de Valle-Inclán», «Don Miguel de Unamuno» y «La barraca ambulante: Baroja, Azorín, A. Machado y el perro, Eugenio d'Ors». ${ }^{7}$ Si los filólogos propugnan que el «Coro de Monos» repita las letras y sus sonidos sin atender a su significado más profundo, La Lechuza, El Ruiseñor y El Mirlo se alían con el «Coro de Pájaros» pues «no admiten explicaciones de palabra». ${ }^{8} \mathrm{Y}$ resulta interesante comprobar, en este sentido, la importancia que contiene la única aparición de Unamuno que podemos encontrar en esta farsa.

En efecto, al final del primer Acto, Unamuno se presenta en el escenario al modo de un «deus ex machina» de la tragedia griega. Así, en la acotación que acompaña a su entrada se dice: «(En esto aparece en el fondo del bosque, azotado por la tempestad, iluminado por los rayos, como un Rey Lear, Don Miguel de Unamuno, que grita, dominando el estruendo de modo que todos le oyen)». ${ }^{9} \mathrm{Y}$ sus palabras, provocadoras y amenazadoras, se harán eco del pensamiento y manera de entender la literatura y la palabra de ambos autores:

M. UNAMUNO. ¡Farsantes! ¡Hipócritas! ¡Fariseos! ¿Qué sabéis vosotros de la palabra? De la palabra viva, sangre y cuerpo de nuestra alma. De la fe, del amor, de la poesía, ¿qué sabéis vosotros? ¡Id a engañar a los tontos con vuestras mercancías, ya que no sabéis descubrir la vida, como los arúspices, en las entrañas palpitantes del idioma. ${ }^{10}$

$\mathrm{Y}$, de esta forma, su entrada y sus palabras provocarán la huida del «Coro de las Fichas» quienes, al precipitarse en el fuego, causarán, a su vez, la devastación de todo el edificio donde trabajaban los filólogos a causa del incendio. Más adelante, comprobaremos la importancia que tiene en el teatro bergaminiano la estructura y los mitos del teatro griego, a través, de nuevo, del saber clásico de don Miguel. Pero lo que nos interesa ahora resaltar es que en esta especial cruzada por el espíritu, Bergamín, ese pájaro negro que aparece como prólogo y epílogo en la farsa, reconoce en su maestro Unamuno ese poder conminatorio que él manifiesta haber perdido tal y como expone el Coro de los Monos al Maestro al principio del tercer acto de la obra:

CORO DE MONOS. El ruiseñor y la lechuza ejercen una gran influencia y todos los pájaros los tienen en veneración.

MAESTRO. Yo temo más al mirlo, porque es un cínico capaz de cualquier cosa con tal de ponernos en ridículo.

\footnotetext{
6 Bergamín, J., Los filólogos, ob. cit., p. 44.

7 Bergamín, J., Los filólogos, ob. cit., p. 44.

8 Bergamín, J., Los filólogos, ob. cit., p. 57.

9 Bergamín, J., Los filólogos, ob. cit., p. 48.

10 Bergamín, J., Los filólogos, ob. cit., p. 48.
} 
CORO DE MONOS. No lo creas. El mirlo, como se burla de todo, ha perdido mucha autoridad. ${ }^{11}$

Debemos tener en cuenta que la lechuza en este caso simboliza a Unamuno, pues su figura se ajusta perfectamente a esa «diosa de la sabiduría», Atenea, a quienes los griegos estudiados por don Miguel, representaban a través de la imagen de dicho pájaro. Y no será la única obra en la que se asocie con él, pues, en el ya mencionado ensayo «Miguel de Unamuno y el santo oficio del escritor», comenta Bergamín al respecto:

¿Por qué no escribe usted como todo el mundo?, suele preguntársenos a los escritores solitarios, solidarios de nuestras comunes soledades propias. Y así se lo preguntaban a Don Miguel. A lo cual responden por nosotros olivos y mochuelos. Porque todo el mundo no escribe; como no lee. Se escribe y se lee para el mundo todo y por el mundo todo; lo cual es hacerlo del todo y para todos en cada uno. Que «cada uno es cada uno» dice nuestro pueblo de Madrid -«el Madrid de la España eterna»-: como el olivo y el mochuelo. Y cada mochuelo a su olivo: a su alero del tejado propio y común; tejado de vidrio, alero de ala y ala de pluma. ${ }^{12}$

Por otro lado, el ruiseñor representa a Juan Ramón Jiménez, poeta admirado por Bergamín hasta que su relación se ve truncada por diversas razones que Nigel Dennis ha estudiado en profundidad..$^{13} Y$ faltaría un cuarto «pájaro»-en este caso un mamífero, más que un ave-, el murciélago, para representar a otro de los autores admirados por el escritor exiliado, don Ramón de Valle-Inclán, quien también aparecerá mágicamente sobre el escenario, a modo de profeta anunciador de las palabras que dirigirá Unamuno en el Centro de los filólogos al final del primer acto: «(De pronto, en la chimenea se levanta una llamarada y aparece fantásticamente un murciélago negro que tiene las barbas y las gafas de Valle-Inclán)». ${ }^{14} \mathrm{Su}$ caracterización como «fantasma» y demonio para el Maestro inefable y sus discípulos no deja de resultar un rasgo positivo en esta obra que satiriza de todas las formas posibles la labor filológica de intentar medir, explicar y constreñir las palabras a meros sonidos sin significado real ninguno.

En Los filólogos no vuelven a salir en escena el personaje de Unamuno ni los otros escritores elegidos por Bergamín para luchar contra el excesivo celo gramatical y filológico de «el Maestro Inefable» y sus discípulos. Pero no olvidemos que su entrada a escena será la que desencadene el incendio del «Centro»-en alusión al lugar y a las tareas que se desarrollaban en el Centro de Estudios Históricos- y que su figura

\footnotetext{
11 Bergamín, J., Los filólogos, ob. cit., p. 55.

12 Bergamín, J., «Miguel de Unamuno y el santo oficio del escritor», en Prólogos epilogales, ob.cit., p. 95.

13 Dennis, N., Perfume and Poison. A Study of the Relations between José Bergamín and Juan Ramón Jiménez, Kassel, Edition Reichenberg, 1985.

14 Bergamín, J., Los filólogos, ob. cit., p. 47.
} 
revolotea en otros momentos de esta obra que recuerda, además, las diatribas del don Miguel hacia eruditos librescos en Amor y pedagogía. Así, cuando en el segundo acto se plantea la reconstrucción de la labor realizada por los filólogos, el maestro responde a las serias dudas del Profesor Tomás Doble de que eso sea posible, diciéndolo: «Que el escepticismo no siembre en ti, querido amigo, su unamunesca pasión efervescente...». ${ }^{15}$ Y sus palabras finalizarán por la llegada de la «Cacatúa», el único pájaro que no reconocen los otros porque se limita a repetir sin saber lo que está diciendo.

Como vemos, en esta «farsa aristofanesca» Bergamín trata uno de sus temas preferidos, la contraposición entre el espíritu y el pie de la letra, asunto que cobra gran relevancia en sus aforismos, ensayos, poesías y en su teatro. De nuevo, las palabras que dedica a Unamuno nos ayudan a entender cómo ambos autores conseguirán aunar, en una nueva paradoja común a los dos, modelos y referencias anteriores con un pensamiento nuevo y creativo:

¿Que no me entiendes bien?-nos pregunta Unamuno-. Pues aprende mi lengua, nuestra lengua o déjalo. Y si la aprendes, si la aprendemos de consuno, deja que así, al desgaire, desencadenemos -esto es, libertemos- lugares comunes para hacérnoslos propios. Y propio el sentido común.

Así, al desgaire, solemos andar los escritores desencadenando, libertando lugares comunes, que, al hacérnoslos propios, vuelven a hacernos comunicables, recuperando su sentido común apropiadamente. «Oye uno para poder hablar -escribe Don Miguel-, lee para poder escribir». ${ }^{16}$

El lenguaje debe ser siempre creador y creativo, lleno de pensamiento y sentimiento por parte del autor, pero también, rico en matices e interpretaciones por parte de quien lo recibe. De ahí, la sátira cruel de Bergamín para quienes, lejos de la opinión de don Miguel, quieren constreñirlo a simples moldes o fichas gramaticales, o bien, diseccionarlo para que pierda su valor y, sobre todo, su espíritu. Por tanto, más próximo estará el lenguaje popular, lleno en matices y acepciones, al ideal literario de ambos escritores, que la «farsa de los filólogos». Así lo evoca y recuerda José Bergamín, con palabras de Unamuno, en una entrevista donde habla sobre el idioma fundamental de su infancia:

Aprendí a escribir oyendo hablar a los analfabetos, rodeado de una servidumbre numerosa procedente de todas las regiones de España, porque los niños andaluces comían en la cocina. Aquellas muchachas contaban chistes, infundios, leyendas de sus aldeas en un lenguaje poético, que constituía mi dialecto literario, que decía Unamuno, siempre dificilísimo de entender de los doctos profesores. ${ }^{17}$

\footnotetext{
15 Bergamín, J., Los filólogos, ob. cit., p. 49.

16 Bergamín, J., «Miguel de Unamuno y el santo oficio del escritor», en Prólogos epilogales, ob.cit., pp. 92-93.

17 Gurméndez, C., «La irreductible personalidad de José Bergamín», en El País, 26 de enero de 1980, suplemento «Artes», p. 13.
} 
Sin duda, además de esa concepción «espiritual» y creadora del lenguaje nos encontremos también en el teatro del escritor madrileño dos aspectos heredados de Unamuno: el placer por jugar con las palabras y huir de clasificaciones prefijadas para la dramaturgia que realizó.

\section{2. «NO SE PIENSA MÁS QUE AFORISMOS O EN DEFINICIONES ${ }^{18}$}

Al igual que los personajes simbolizados por «pájaros» en su comedia Los filólogos, José Bergamín concebirá toda palabra como llena de significados. De ahí que considere su obra teatral como un medio ideal para «dar que pensar». Ejemplos de un teatro casi aforístico y lleno de dobles matices y significados resultan sus primeros intentos teatrales, Enemigo que huye, Tres escenas en ángulo recto o la misma farsa comentada en el apartado anterior. Pero también en una de sus últimas obras conservadas, La cama, tumba del sueño o El dormitorio, fechada en 1956, nos encontramos con diálogos llenos de paradojas y juegos de palabras, de ideas cruzadas y repensadas para que dejen de ser lugares comunes y se conviertan en «propios»:

ÉL. Tanto mejor. Nadie se conoce antes de encontrarse.

ELLA. ¿De encontrarse cómo?

ÉL. Como nosotros. Como ahora tú y yo. Por la primera vez...

ELLA. Cuando uno se encuentra es siempre por la primera vez.

ÉL. Por primera vez nos encontramos ahora en esta alcoba; pero sin saber cómo ni por qué.

ELLA. Se nos habrá olvidado.

ÉL. Es posible. Hagamos algo para recordarlo.

ELLA. ¿Recordar qué?

ÉL. Esto. Por qué estamos aquí, los dos. Cuándo vinimos, y de dónde. ${ }^{19}$

Las réplicas breves, cargadas de palabras con más de un matiz y llenas de significados no son exclusivas de este tipo de teatro que podría ser considerado más filosófico. Bergamín recurre al gusto por descomponer y ofrecer los temas en su más amplia gama de acepciones en casi todas las obras dramáticas que escribió. Como vemos, la idea de pensar y dar que pensar proviene de esa concepción aforística del pensamiento que el autor exiliado recibió de su maestro, don Miguel. Solo repasando los títulos o los nombres de algunos personajes de sus composiciones teatrales podremos

18 Cita de Unamuno que Bergamín recoge en BERGAMÍN, J., «El rabo ardiendo», en Escritura, Montevideo, 7, junio de 1949, p. 43.

19 Bergamín, J., La cama, tumba del sueño, Primer Acto, Madrid, 198, marzo-abril de 1983, pp. 71-72. 
empezar a comprender cómo el hecho de jugar con las palabras conlleva un grado de compromiso tan serio como formalmente adquirido por los dos escritores.

En efecto, ya en la primera obra teatral publicada en el exilio, Tanto tienes cuanto esperas y el cielo padece fuerza o La muerte burlada (Misterio de la fe y dolorosa pasión de Santa Catalina de Siena ${ }^{20}$ nos encontramos con un título lleno de profundos significados y acepciones. No resulta extraño que, recién iniciado su exilio, nuestro autor elija el género dramático como el más idóneo para sus inquietudes literarias. En primer lugar, parece curioso que escriba un «misterio de fe» en un momento en que las heridas de la Guerra Civil española se mantenían abiertas en la todavía vigente II Guerra Mundial. Sin embargo, no olvida nuestro autor su «ministerio literario» al escribir esta pieza, en la que sus preocupaciones religiosas y sociales del momento se compaginan con el modelo de las vidas de santos que escribió Lope (Santa Teresa de Jesús o El viaje del alma) o autos como La nave del mercader de Calderón. La acción se sitúa en Siena, en el siglo XIV, pero Bergamín no se olvida de recordarnos la situación presente en que redactó e ideó su obra. Por otro lado, el título de la obra sigue el gusto de José Bergamín por rescribir frases populares, literarias o evangélicas. Así, el primero de los tres títulos juega con una expresión hecha, al estilo de la que utilizó Miguel Hernández para titular su auto como Quien te ha visto y quién te ve y sombra de lo que eras. ${ }^{21} \mathrm{Y}$ el propio escritor madrileño nos recuerda el pasaje de Don Quijote de donde ha tomado el primero de los subtítulos. Se trata, en efecto, del capítulo 58 de la Segunda parte de la novela de Cervantes y, en concreto, del momento en que se encuentra con cuatro santos de palo o caballeros andantes a lo divino: San Jorge, San Martín, San Diego o Santiago Matamoros y San Pablo. No deja de ser significativo que al recordarlo, evoque también la opinión que sobre él tenía don Miguel de Unamuno:

Todo en el libro admirable de su vida parece equilibrarse, de veras y de burlas, en esta tragicómica pugna del heroísmo y la santidad. Por eso en este pasaje, que Unamuno llama abismático, vemos decidirse por boca del mismo Don Quijote esta diferencia, cuando encarándose con los santos nos afirma: que la diferencia que hay

\footnotetext{
20 BERGAMín, J., «Tanto tienes cuanto esperas y el cielo padece fuerza o La muerte burlada (Misterio de la fe y dolorosa pasión de Santa Catalina de Siena», en Hijo Pródigo, México, I época, 10, enero de 1944, pp. 40-53, donde se publican el primer y segundo acto; y 11, febrero 1944, pp. 107-119, en el que aparecen el tercer acto y los dos epílogos. Todas las obras de su etapa del exilio que aparecen referenciadas en este artículo pueden consultarse también en: SANTA MARía, M.T., El teatro en el exilio de José Bergamín. Tesis doctoral, II, Bellaterra, UAB, 2001, pp. 587-1036.

21 Como solía ser habitual, pudo influir el Bergamín editor en la elección definitiva del título de la primera obra teatral del poeta de Orihuela. Así parece desprenderse de la carta que Miguel Hernández envía a nuestro autor en junio de 1934: «He llegado al cabo de mi obra que quise hacer sacramental. Para la mitad de esta semana que se nos echa encima, le mandaré lo hecho que le falta [...] Ahí van esos dos nombres: "iQuién! te ha visto y iquién! Te ve" y "El Hombre, asunto del cielo". Si tiene, amigo Bergamín, alguno y no le son bien parecidos éstos dígamelo» (RoviRA, J. C., «Introducción» en HeRnÁNDEZ, M., Obra completa, II: Teatro, Madrid, Espasa-Calpe / Generalitat Valenciana / Caja de Ahorros del Mediterráneo, Clásicos Castellanos, 28, 1992, p. 1180).
} 
entre mí y ellos es que ellos fueron santos y pelearon a lo divino y yo soy pecador y peleo a lo humano. Ellos conquistaron el cielo a fuerza de brazos, porque el cielo padece fuerza, y yo hasta ahora no sé lo que conquisto a fuerza de mis trabajos. ${ }^{22}$

El último de los subtítulos se explica a lo largo de la obra pero, ya desde el principio, nuestro autor le otorga una interpretación cristiana a partir de la frase tomada de San Pablo: «Muerte, ¿dónde está tu victoria? ¿Dónde, muerte, tu aguijón?».23 Utiliza también este epígrafe en uno de sus poemas dedicados a Claudine ${ }^{24} \mathrm{y}$ era pensamiento común en nuestro autor, pues reformula la idea en Medea: «¡Muerte! ¡Imposible afán de una ilusoria sombra / que arrastra su esqueleto de sueño por el suelo! / ¿Dónde está tu aguijón, tu veneno, tu engaño, / la miel de este panal vacío de mi cuerpo? / ¿Dónde se pudre el alma cuando tus sueños huyen? / ¿Dónde la victoriosa razón de tu misterio?». ${ }^{25}$ Sin duda, Cristo, al vencer a la muerte, se burló de ella, y por esta razón Santa Catalina invita a Tuldo a seguir su ejemplo aceptando con gusto y como un bien su final.

Por su parte, en La hija de Dios ${ }^{26}$ nos ofrecerá como título el nombre real de un pueblo de la paramera abulense que quedará asolado a principios de la Guerra Civil española en el texto bergaminiano. Y su protagonista, Teodora, lejos de constituir la reina de su modelo griego, la última reina de Troya, Hécuba, será una humilde mujer que verá destruida toda su paz, su familia y su tierra. «Teodora» no será ningún regalo o hija de Dios, como la etimología de su nombre o de su pueblo podía sugerir. Aunque, naturalmente, nuestro escritor jugará su última baza al final de la obra, para darnos a entender que este personaje ofrecerá su martirio, como el «Hijo de Dios», Jesucristo, en remisión por su pueblo y ejemplo de la lucha que deben realizar.

También sugerente resulta el título de Medea, la encantadora pues, según Bergamín, contemplaremos «lo que nadie pudo ver jamás de Medea: su desencanto» ${ }^{27}$ y le preguntaremos desde el principio, junto al Ama: « ¿Por qué dudas ahora de ti misma, Medea?», ${ }^{28}$ es decir, ¿cómo has pasado de encantadora a desencantada? Por

\footnotetext{
22 Bergamín, J., «Como sobre ascuas», en El pensamiento perdido, páginas de la guerra y del destierro, Madrid, Adra, 1976, pp. 202-203, donde habla de La Vida de don Quijote y Sancho de su querido Miguel de Unamuno.

23 Corintios 15,55 .

24 Bergamín, J., Poesía, II. La claridad desierta, Madrid, Turner, 1983 p. 94.

25 Bergamín, J., Medea, la encantadora, «explosión trágica en un acto», Primer Acto, Madrid, 44, 1963, pp. 25-26.

26 Bergamín, J., La hija de Dios y La niña guerrillera, Madrid, Hispamerca, 1979, pp. 5-73. Aunque la primera edición de La hija de Dios y La niña guerrillera corresponde a México, M.E.D.E.A, 1945.

27 Bergamín, J., Medea, la encantadora, ob. cit., p. 30.

28 Bergamín, J., Medea, la encantadora, ob. cit., p. 26.
} 
tanto, el calificativo en el título de «encantadora» sintetiza muy bien todo el contenido de la obra. Nada menos encantador o atrayente que la figura de una hechicera y filicida. Y nada más original que mostrar no ya los encantos o conjuros de la maga -condición además indispensable para Eurípides al concebir su personaje como «bárbara» en el sentido etimológico de la palabra-, sino, precisamente, su «desencanto», el momento de estallido o «explosión trágica» que le lleva a unos nuevos crímenes para volver a ser Medea, la divina, la nieta del dios Sol que, libre de toda traba y amor sangriento, regresa a sus orígenes, a los cielos. Pero no acaba aquí de jugar con los «espíritus» de las palabras nuestro dramaturgo. Y así, no estuvo desencaminado Bergamín en la dedicatoria de la obra: «a Dahd Sfeir, que encantó de vida y de verdad el fantasma de esta Medea», ${ }^{29}$ jugando con el significado general de la obra y, en último extremo, con el fin principal del teatro, tal como él lo concebía, «encantar», mostrar desde el principio una ficción, un verdadero «juguete trágico», en el sentido de que «el teatro no realiza nada; lo irrealiza todo» (p. 36), porque, en definitiva, toda la pieza consiste en un «mero pretexto para una actriz», (p. 35). Pero Bergamín no sería Bergamín si no supiese aunar paradójicamente la contradicción de presentar en un simple juego, «lo más hondo, secreto y entrañable de la conciencia humana».

Múltiples referencias literarias aparecen también en el triple título de Melusina y el espejo o una mujer con tres almas y Por qué tiene cuernos el Diablo. Esta «figuración bergamasca» ${ }^{31}$ alude a dos aspectos muy vinculados con la personalidad de nuestro escritor. Por un lado, recuerda el apego de Bergamín hacia el personaje de Arlequín, por proceder de la ciudad italiana de Bérgamo, de donde manifestaba que era originario su apellido; ${ }^{32} \mathrm{y}$, por otro, destaca su afecto hacia ese «espíritu elemental» que tan bien supo ejemplificar el alma femenina y a la que dedicará más atención en otros escritos suyos. Al igual que en Tanto tienes, el título de esta pieza aparece repartido en tres sugerentes partes: Melusina y el espejo o Una mujer con tres almas y Porqué tiene cuernos el diablo. Coinciden, por su parte, cada uno de estos epígrafes con el posible título que hubiera podido dar Bergamín a cada uno de los actos en que se divide la obra, titulación que sí aparece e incluye expresamente en La niña guerrillera. Y así, el primer acto correspondería a la rotura de ese espejo por parte de la protagonista, el segundo a la realización de su «triple» venganza, mientras que en el tercero encontraríamos

\footnotetext{
29 Bergamín, J., Medea, la encantadora, ob. cit., p. 23.

30 Bergamín, J., «Musaraña del teatro», en El pasajero, peregrino español en América, III, México, Séneca, otoño 1943, p. 16.

31 Bergamín, J., «Melusina y el espejo o una mujer con tres almas y Por qué tiene cuernos el Diablo», en Escritura, Montevideo, 10, diciembre 1952. Aunque sus dos primeros actos ya se habían editado en la citada publicación periódica, en el número 8 (diciembre 1949), pp. 28-53; y 9 (noviembre 1950), pp. 21-48, respectivamente.
}

32 González Casanova, J. A., Bergamín a vista de pájaro, Madrid, Turner, 1995, p. 67. 
el «bosquejo» o «encornudamiento» del diablo. Se atienen los tres perfectamente al esquema de Planteamiento-Nudo-Desenlace, aunque también podrían definirse los dos últimos actos como los de la burla al mundo y al diablo, respectivamente, por parte de Melusina. En última instancia, se trataría, además, de mostrar una versión totalmente irónica y distorsionada del tema del honor, la venganza y los cuernos burlados que tanta raigambre -en serio o en broma- tiene en la literatura española. ${ }^{33}$ Reflexión profunda en una farsa en que las citas y las referencias a modelos de cualquier género, siglo y país son numerosas.

No quedaría la relación completa si no citamos, al menos, otros títulos de obras dramáticas suyas donde los juegos de palabras, la etimología y la alusión a obras anteriores resulta también manifiesta. En el teatro anterior a la Guerra nos encontramos con Tres escenas en ángulo recto y Enemigo que huye. Esta última incluye Polifumo, donde los personajes de Hamlet, Fausto y Don Juan se dan cita, respectivamente, en cada una de sus tres partes; y Coloquio espiritual del pelotari y sus demonios, cuyo protagonista, Eautontimorumenos, procede de «El atormentador de sí mismo» de Terencio. Pero también juega en La sangre de Antígona, no solo con un mito clásico, sino con la propia contradicción de quien niega en su propio nombre el linaje o sangre heredados y que debe perpetuar ('anti', «contra»y 'goné', «linaje descendencia»). En ¿A dónde iré que no tiemble? recoge el título del lema de la ciudad de Guatemala para aludir a la situación real de la ciudad de Antigua, anegada por las inundaciones y el volcán del Agua en 1521, pero también a la crisis religiosa que sufre su protagonista, doña Beatriz de Alvarado, «la Sin Ventura», quien regentaba el cargo de gobernadora de Guatemala en ese decisivo momento. En Los tejados de Madrid o El amor anduvo a gatas mezcla entre las silvas de La Gatomaquia de Lope de Vega sus propios versos para ironizar, sin duda, sobre la cita y presunción admirativa que nos ha llegado sobre este autor del Siglo de Oro: «iEs de Lope!».

Como hemos podido comprobar ya por los títulos de algunas de sus obras, la preferencia de Bergamín por las citas o por los modelos literarios anteriores le llevan a un tipo de teatro aforístico y repleto de pensamientos profundos entre juegos con las palabras para convertirlas en «lugares propios», tal y como quería su estimado don Miguel. Pero un concepto más elevado se esconde también en su concepción dramática, tal y como veremos a continuación.

33 Calderón y Valle-Inclán se encontrarían en el vértice de ambas posturas. Por otro lado, no podemos olvidarnos de otras versiones paródicas de «cornudos» que nos han dejado otros contemporáneos de Bergamín, como García Lorca en su Retablillo de don Cristóbal - en la que también se alude explícitamente a personajes de guiñol como «don Arlequín de Bérgamo» (GARCíA LoRCA, F., «Prólogo dialogado» a Retablillo de don Cristóbal, en Obras completas, II, M. García Posada (ed.), Madrid, Galaxia Gutenberg / Círculo de Lectores, 1996, p. 411) - o en Amor de don Perlimplín con Belisa en su jardín; ni de planteamientos más trágicos sobre la cuestión del honor, como los que aparecen en El adefesio de Alberti y Crimen de Max Aub. 


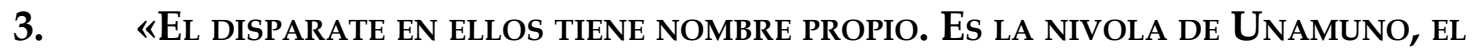

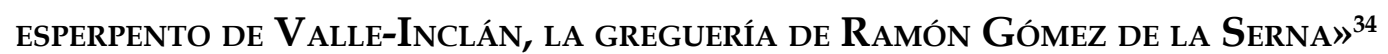

Sin duda, el concepto unamuniano con el que más sintonizaba el autor madrileño sería el de un teatro «humanizado», al afirmar que:

Si la obra genial no envejece es por ser, como la realidad misma, enteramente docente y educativa siempre. El teatro es docente, escuela de costumbres por ser espejo de ellas, y para enseñar al pueblo hay que aprender primero de él, como para domar las fuerzas naturales precísase primero sostener a su estudio la mente. ${ }^{35}$

Si Unamuno recrea y cristianiza unamunescamente a Fedra, ${ }^{36}$ Bergamín se permitirá «cristianizar», con estilo propio, a Antígona. Eso sí, manifestando idéntica pasión por la paradoja que la que guardaba don Miguel y que tan grata era, por naturaleza, a Bergamín: «¿Si los muertos no quieren mi vida, por qué quieren los vivos mi muerte?». ${ }^{37}$ Paradójica pregunta que puede servir como espejo donde se reflejase el mismo Unamuno. No constituirá esta la única ocasión en que, por otro lado, el autor exiliado mantenga viva la antorcha grecolatina que encendió don Miguel al inaugurar, con su versión de Medea y la magnífica actuación de Margarita Xirgu, los festivales del Teatro Clásico de Mérida en 1933. En efecto, tal y como hemos aludido con anterioridad, Bergamín escribió Medea, la encantadora y se remontó al mito de Hécuba de Eurípides, a través también de Hécuba triste de Fernán Pérez de Oliva, a la hora de escribir La hija de Dios.

Y, en este caso, la incorporación de mitos clásicos no se ceñirá a una mera búsqueda de lugares propios, sino que subyace toda una concepción dramática que, como vemos, tiene muy en cuenta las directrices de su maestro Unamuno. Así lo comprobamos, por ejemplo, en una de las definiciones que sobre lo que es teatro nos dejó Bergamín:

El teatro es grito, como afirma certeramente don Miguel de Unamuno, y alguno tiene que acabar -o empezar- por salir gritando; por eso, cuando no empieza por gritar el drama, la comedia, acaba por gritar el público. [...] ¿Qué hacen Esquilo y Shakespeare o Calderón, sino gritar engañosamente? Gritar de lo que les duele el engaño. El teatro es grito por la palabra o por el gesto; la máscara en un grito para los ojos antes de serlo, por su resonancia de la voz para los oídos: haciéndose

\footnotetext{
34 BerGAMín, J., «El disparate en la literatura español» en Al fin y al cabo (prosas), Madrid, Alianza, 1981, p. 51.

35 Unamuno, M. de, «La regeneración del teatro español», en Teatro completo, M. García Blanco (ed.), Madrid, Aguilar, 1959, pp. 1144-1145; recogido por GonZÁlezZ Del Valle, L., La tragedia en el teatro de Unamuno, Valle-Inclán y García Lorca, Nueva York, Eliseo Torres Sons, 1975, p. 24.

36 Estrenada en el Ateneo de Madrid el 25 de marzo de 1918 ( $c f$. UnAmuno, M. de, «Exordio» a Fedra, en La esfinge. La venda. Fedra Madrid, Castalia, Clásicos Castalia, 169, 1988, p. 185).

37 Bergamín, J., La sangre de Antígona, Primer Acto, Madrid, 198, marzo-abril 1983, p. 53.
} 
por lo visto y oído entendido; transmitiendo el grito del pensamiento, del pensar mentido, fingido, figurado, que es lo dramático: vestido, máscara del pensar. ${ }^{38}$

Esta concepción del teatro como medio para enmascarar y ofrecer los pensamientos más profundos e inquietantes del hombre aparece en otros textos del Bergamín ensayista o teórico. Tal es el caso de «La cólera española y el concepto lírico de la muerte», donde encontramos, además, otro tema unamuniano que intentará colocar sobre las tablas escénicas:

La razón era una pasión para el griego: una pasión humana; la pasión es una razón para el cristiano, una razón divina. De este modo se le representaba al griego, en su teatro, una verificación de la muerte, por la razón, que es el desesperado y desesperante sentimiento trágico de la vida, como le ha llamado Unamuno; mientras que al español del XVII lo que se le representa en su teatro es una verificación de la vida por la fe, que es una esperanzada y esperanzadora concepción lírica de la muerte. Por eso el teatro griego se convertía, por su verdad, en un vivo teatro de la muerte, como le diría Calderón. En cambio, el teatro católico español del XVII, se hizo, por la muerte, un verdadero teatro vivo: un poético torcedor del pensamiento. ${ }^{39}$

Nos encontramos aquí con un rasgo fundamental del teatro bergaminiano que trasluce una de las ideas más recordadas a propósito de Unamuno. En efecto, los protagonistas dramáticos de Bergamín se constituirán en verdaderos «agonistas» que luchan y buscan una salida a su angustia y a su «sentimiento trágico de la vida». Conseguirá de esta forma dos propósitos ineludibles respecto a su labor como dramaturgo. En primer lugar, puede respetar las directrices de los dos momentos clave para él del teatro universal: la tragedia grecolatina y el drama del Siglo de Oro. $\mathrm{Y}$, en segundo, consigue plantear la posibilidad de que exista una tragedia tras el cristianismo. En efecto, para el pensador madrileño la venida de Jesucristo supuso el final de la tragedia y la llegada del drama sobre los escenarios. En su opinión, el libre albedrío frente a un destino implacable, la providencia divina en oposición a una culpa heredada, el castigo por una afrenta justa o injusta en contra de la salvación del alma para todo aquel que se arrepiente habían desterrado la tragedia o lo trágico de las tablas escénicas. Esta concepción religiosa del teatro y lo teatral es inmanente a su labor dramática y también la que le lleva a plantear que, precisamente, la imposibilidad para algunos de poder creer en ese Dios hecho hombre que nos salva, fue lo que propició el regreso de la tragedia y del sentimiento trágico en el hombre contemporáneo:

Santa Teresa de Ávila nos dejó también dicho aquello de que unas almas se purifican al arder y otras se consumen; palabras magistralmente definidoras de la experiencia entre la ansiedad y la angustia que tan poderosamente nos describe la otra genial

\footnotetext{
38 Bergamín, J., «Ramón y el eco», en Prólogos epilogales, ob. cit., pp. 73-74.

39 Bergamín, J., «La cólera española y el concepto lírico de la muerte», en Detrás de la cruz, terrorismo y persecución religiosa en España, México, Séneca, 1941, p. 102.
} 
analfabeta [Santa Catalina] de Génova en su Tratado [...] Angustia y ansiedad, consumiendo y purificando esas almas, esas encendidas conciencias, pulsan con tal ritmo su cristiana agonía. Siglos después encontrará acentos parecidos a esos de místicos y santos la palabra agónica del cristianismo en Miguel de Unamuno. Su conciencia responde al eco de otra ansiosa y angustiosa agonía del pensar cristiano: la del danés Kierkegaard. Pero antes que ellos ya nos había dejado en fragmentos escalofriantes de tan puro arder espiritual esta misma angustiosa espera, ansiosa y cristiana agonía de su pensamiento, en pensamientos, Pascal. ${ }^{40}$

Se enlazan, otra vez a partir de una idea unamuniana, «no hay esperanza sin recuerdo», ${ }^{41}$ dos elementos presentes en el teatro de Bergamín. Por un lado, los «recuerdos» de obras, mitos y personajes anteriores de los que ya hemos dejado constancia en las páginas previas. Y, por otro, la incorporación de esos auténticos «agonistas» que, como nuevos «Augusto Pérez» se preguntarán por su pasado, su futuro y su propia esencia y presencia en el mundo. Personajes que, en algunos casos, se dejarán llevar por la desesperación, como les ocurre a Antígona, Teodora o a doña Beatriz de Alvarado; mientras que en otros parten, como Tuldo en Tanto tienes o Medea, hacia un cielo poblado por la divinidad y por el amor:

JASÓN. [...] ¡Huye, Medea! ¡Huye, adonde no pueda verte jamás!... ¡Y ojalá los más altos cielos adonde subas los encuentres vacíos de sus Dioses: para llenarlos de tu odio!...

MEDEA. ¡Para llenarlos de mi amor! ¡Oh!, ¡qué angustioso, qué desesperado, divino vacío de amor! ¡La ansiedad de mi alma por llenarlo es más honda que los más altos cielos! ¡Mi amor es más puro que la voz callada de sus astros!... ¡Mi amor solo es eterno! ¡Con este puro amor, sin sangre, con este puro fuego, voy a llenar los cielos con mi amor: de amor, de amor, de amor, de amor, de amor!... ¡A ti, Padre celeste, voy! ¡Tú, El Solo, guíame!... ¡Voy a poblar tu eterna soledad divina de humana soledad de amor!...42

Y al igual que Bergamín no permitirá que la última palabra de su Medea la pronuncie Jasón para dejarnos a merced de la desesperanza, deseará idéntico desenlace redentor para su maestro don Miguel cuando afirma que «el sueño final de Unamuno, aun desesperado ante el espectáculo sangriento, desastroso, de su España querida y soñada, no puede perderse en un cielo desierto, vacío». ${ }^{43}$ Palabras que recuerdan, precisamente, el verso final de Séneca que el profesor y escritor vasco

\footnotetext{
40 Bergamín, J., «El pozo de la angustia» en El pensamiento perdido, páginas de la guerra y del destierro, Madrid, Adra, 1976, pp. 166-167.

41 Alude a ella Bergamín en «La máscara y el rostro. Cristal y noche de los tiempos (Mito. Historia. Poesía)», en Escritura, 6, enero de 1949, p. 20. También aparece esa vinculación entre esperanza y recuerdo en BERGAMín, J., «Cristal del tiempo, II: añoranza y esperanza», en El pasajero, peregrino español en América, I, primavera, 1943, México, editorial Séneca, pp. 77-88.
}

42 Bergamín, J., Medea, la encantadora, ob. cit., p. 35.

43 Bergamín, J., «Unamuno, el hereje», en De una España peregrina, Madrid, Al-Borak, 1972, p. 85. 
tan bien conocía y esa dualidad perenne de España que Bergamín de nuevo recoge, a través de su maestro, de otro autor clásico nacido en España: «Por eso nos recordaba siempre Unamuno aquel verso latino del español, andaluz, Lucano, en su Farsalia, en el que hace alusión a una constante Guerra Civil entre españoles, que es más -dice el poeta- mucho más que guerra civil: porque es como un trágico destino común, una fatalidad que respondiese a una entrañable, ineludible, paradójica, afirmación mortal de la vida». ${ }^{44} \mathrm{Y}$ no se puede esperar otra cosa del autor exiliado que retoma de nuevo ese testigo literario y nos deja su visión cambiante pero exhaustiva sobre la Guerra Civil que le tocó vivir en tres de sus obras teatrales: La hija de Dios, La niña guerrillera y La sangre de Antígona.

Sin duda, nada mejor para acabar con el santo oficio divino de ambos escritores que terminar este artículo con la obra que nos ofrece la visión más esperanzada, recordada y clásica de la Guerra Civil pero también de un mito que, para cerrar el círculo dramático de un anfiteatro griego, debe buena parte de su difusión al, en otro momento satirizado, maestro don Menéndez Pidal. En efecto, el romance de «La doncella que fue a la guerra» le sirve como melodía de fondo, al estilo de la canción sobre el caballero de Olmedo en Lope de Vega, para La niña guerrillera. Como decíamos constituye este drama un canto a la esperanza y a la transmisión de un legado no solo literario y popular, sino histórico. A la «Niña» de Bergamín le sucederán otras niñas a causa de esa maldición que ya predecía Lucano en su Farsalia. De igual forma, la protagonista bergaminiana de este «romance» rememora la inocencia y valentía de esa doncella guerrera que nos ha llegado a través de la tradición oral. Como una flor que vence cada primavera al invierno y a las nieves, nos la describe Bergamín para evitar caer él también en el cielo vacío de dioses al que había precipitado en sus otras obras sobre la Guerra Civil a todo un pueblo -en La hija de Dios- ; o a su protagonista -en La sangre de Antígona-.

Pero, además, en el «Prólogo-Epílogo-Apostillas» que Bergamín escribió para el estreno de La niña guerrillera en el Teatro Artigas de Montevideo, nuestro dramaturgo nos ofrece, una vez más, su peculiar manera de entender las tablas y diablas escénicas. $\mathrm{Y}$, desde luego, tampoco en esta ocasión podía faltar su maestro para matizar y definir mejor los términos de «lo que es teatro y lo que no»:

Se hizo también otra especie de axioma teatral, el que corría hace algunos años por París -y que no recuerdo a quien se debe- de que hay que volver a teatralizar el teatro. Como si el realismo y naturalismo lo hubiesen desteatralizado. Bastaría citar a Ibsen, Bernard Shaw, D’ Annuzzio... y Pirandello, para comprenderlo. Entre nosotros -digo en lengua española- a Galdós, Benavente, los hermanos Álvarez Quintero, Arniches... sin excluir a Valle Inclán y Unamuno. Recuerdo que este

44 Bergamín, J., «Musaraña y duende de Andalucía», en De una España peregrina, ob. cit., pp. 168-169. 
último me decía que no le gustaba la adaptación escénica que le había hecho un gran amigo suyo de su novela: Nada menos que todo un hombre, porque -me decía- que la encontraba demasiado teatral o teatralizada, con lo que le parecía a él, falseada o falsificada en su verdad. Leyendo otras obras teatrales suyas (Fedra, El otro, Don Juan) advertimos que su esquelética contextura dramática no llegaría fácilmente desde el escenario hasta el espectador; no llegaba en efecto. Pero «el teatro es grito» -decía Unamuno- y ese, su propio «lenguaje de hueso trágico» en el escenario, grita de verdad. ¿Entonces, este teatro de verdad no es teatro de verdad? Pues, ¿qué es teatro ${ }^{45}$

¿Una nueva coincidencia entre dos personajes y escritores heterodoxos, fieles a sí mismos y a las circunstancias que les tocaron vivir? Porque el teatro de Bergamín, como el de Unamuno, es tan teatro de verdad que no acaba de ganar espacio sobre el escenario para llegar a ser representado o «encantado». Ironías, aforismos, juegos de palabras con los títulos o los personajes; eclecticismo en los géneros y en los modelos que utilizan para conseguir una «nivola» o un «drimo» si no somos capaces de reconocerles que ambos fueron, al fin y al cabo, hombres de teatro.

\section{BIBLIOGRAFÍA}

AA.VV., «José Bergamín. Un teatro peregrino», en Cuadernos El Público, 39, Madrid, abril 1989.

BERGAMíN, J., «La decadencia del analfabetismo», en Cruz y Raya, Madrid, 3, junio 1933, pp. 61-94.

, Detrás de la cruz, terrorismo y persecución religiosa en España, México, Séneca, 1941.

«Cristal del tiempo, II: añoranza y esperanza», en El pasajero, peregrino español en América, I, México, editorial Séneca, primavera 1943, pp. 77-88.

«Musaraña del teatro», en El pasajero, peregrino español en América, III, México, Séneca, otoño 1943, pp. 9-27.

Tanto tienes cuanto esperas y El cielo padece fuerza o La muerte burlada, El Hijo Pródigo, México, I época, 10, enero de 1944, pp. 40-53; y 11, febrero 1944, pp. 107-119.

, «La máscara y el rostro. Cristal y noche de los tiempos (Mito. Historia. Poesía)», en Escritura, 6, enero de 1949, pp. 16-22.

, «El rabo ardiendo», en Escritura, Montevideo, 7, junio de 1949, p. 43.

«Melusina y el espejo o una mujer con tres almas y Por qué tiene cuernos

el Diablo», en Escritura, Montevideo, 10, diciembre 1952. Primer acto de la

45 Bergamín, J., «Prólogo-Epílogo-Apostillas a La niña guerrillera», en Boletín de Información del Retablillo Español, Montevideo, I, 1, enero 1954, p. s/n. 
obra: en Escritura, 8, diciembre 1949, pp. 28-53; y segundo acto: en Escritura, 9, noviembre 1950, pp. 21-48.

Medea, la encantadora, «explosión trágica en un acto», Primer Acto, Madrid, 44, 1963, pp. 23-36.

, El pensamiento perdido, páginas de la guerra y del destierro, Madrid, Adra, 1976, pp. 166-167.

La hija de Dios y La niña guerrillera, Madrid, Hispamerca, 1979. Edición facsímil de la publicada en México, MEDEA, 1945.

, Al fin y al cabo (prosas), Madrid, Alianza, 1981,

La sangre de Antígona, La cama, tumba del sueño, Primer Acto, Madrid, 198, marzo-abril de 1983, pp. 48-80.

, Poesía, II. La claridad desierta, Madrid, Turner, 1983.

, «Miguel de Unamuno y el santo oficio del escritor», en Prólogos epilogales,

Nigel Dennis (ed.), Valencia, Pre-Textos, 1985, pp. 91-97.

, Teatro de vanguardia (Una noción impertinente), Paola Ambrosi (ed.), Valencia,

Pre-Textos, 2004. Contiene las piezas dramáticas: Tres escenas en ángulo recto, Enemigo que huye y Los filólogos.

DennIs, N., Perfume and Poison. A Study of the Relations between José Bergamín and Juan Ramón Jiménez, Kassel, Edition Reichenberg, 1985.

GonzÁlez Casanova, J. A., Bergamín a vista de pájaro, Madrid, Turner, 1995.

GonzÁlez del Valle, L., La tragedia en el teatro de Unamuno, Valle-Inclán y García Lorca, Nueva York, Eliseo Torres SONS, 1975.

GURMÉNDEZ, C., «La irreductible personalidad de José Bergamín», en El País, 26 de enero de 1980, suplemento «Artes», p. 5 y 12-14.

SANTA María, M. T., El teatro en el exilio de José Bergamín. Tesis doctoral, Bellaterra, UAB, 2001, dos volúmenes.

Unamuno, M. de, «Exordio» a Fedra, en La esfinge. La venda. Fedra, Madrid, Castalia, Clásicos Castalia, 169, 1988. 